\title{
Pengaruh Debt To Asset Ratio, Inventory dan Earning Per Share terhadap Harga Saham pada Industri Subsektor Farmasi yang Terdaftar di BEI
}

\author{
Umar Hamdan Nst", Syamsurizal, Cut Zahri \\ Universitas Dharmawangsa Medan \\ Jl. KL. Yos Susarso No.224, Medan, Indonesia \\ *Correspondence email: Umarhamdan@dharmawangsa.ac.id
}

\begin{abstract}
Abstrak. Riset ini bermaksud untuk memahami dampak Debt to Assets Ratio, Inventory Turnover dan Earning Per Share terhadap Harga Saham Pada Perusahaan Subsektor farmasi yang listing di BEI Periode 2015 - 2019. Populasi riset yang dipakai sebesar 9 emiten dan jumlah sampel sebanyak 45 sampel. Metode riset memakai statistik kuantitatif. Metode analisis data memakai tes asumsi klasik. Tes hipotesis dengan tes regresi, t-test, dan f-test. Berdasarkan hasil tes parsial (t), DAR dan ITO tidak berpengaruh terhadap harga saham namun EPS memiliki pengaruh terhadap harga saham. Sedangkan hasil tes simultan (f) DAR, ITO dan EPS tidak berdampak terhadap harga saham. Perolehan test hipotesis Adjusted R Square (R2) sebanyak 21\%, maka dapat dikatakan variabel Debt to Assets Ratio (X1), Inventory Turnover (X2) dan Earning Per Share (X3), berpengaruh terhadap Harga Saham sebesar 21\% dan selebihnya sebesar 79\% dipengaruhi oleh variabel lain yang tidak terdapat dalam riset ini.
\end{abstract}

Kata kunci: Debt to Assets Ratio; Earning Per Share; Harga Saham; Inventory Turnover

Abstract. This research understands the impact of Debt to Assets Ratio, Inventory Turnover and Earning Per Share on Share Prices in pharmaceutical subsector companies listed on the Indonesia Stock Exchange for the 2015-2019 period. The research population used was 9 issuers and a total sample size of 45 samples. Statistical research methods use quantitative. The assumption data analysis method is the classical assumption test. Hypothesis test with regression test, $t$-test, and f-test. Based on the results of the partial test (t), DAR and ITO have no effect on stock prices but EPS has an effect on stock prices. Meanwhile, the simultaneous test results $(f)$ of DAR, ITO and EPS have no impact on stock prices. The result of the Adjusted $R$ Square (R2) hypothesis test is 21\%, it can be said that the Debt to Assets Ratio (X1), Inventory Turnover (X2) and Earning Per Share (X3) variables have an effect on stock prices by $21 \%$ and the rest is $79 \%$. audits by other variables not included in this research

Keywords: Debt to Assets Ratio; Earning Per Share; Inventory Turnover; Stock Prices

\section{PENDAHULUAN}

Setiap perusahaan yang ingin mengembangkan usahanya pasti membutuhkan modal. Upaya yang dipakai eaten adalah dengan menawarkan sahamnya kepada masyarakat atau disebut dengan go public. Go Public yaitu upaya yang dilaksanakan emiten dalam memperoleh dana ekstra demi peningkatan dana yang dihasilkan oleh emiten go public. Emiten yang go public bisa menawarkan sahamnya di Bursa Efek sesuai dengan harga yang telah ditentukan atau disebut dengan harga saham. Harga saham adalah parameter keinginan calon investor untuk membeli saham emiten, bila harga saham emiten meningkat, maka investor atau calon investor menilai bahwa emiten mencapai keberhasilannya dalam menjalankan usahanya.

Dalam riset ini, sampel yang dipilih adalah perusahaan subsektor farmasi yang terdaftar di BEI. Hal ini disebabkan, industri farmasi saat ini sedang mengalami peningkatan yang cukup signifikan dimana dimasa pandemi covid-19 omzet penjualan obat-obatan melambung tinggi. Berdasarkan data yang diperoleh dari BEI, dalam sepekan terakhir Indeks Harga Saham Gabungan (IHSG) menguat $0,84 \%$ kendati di Jumat (6/3) ditutup minus hingga 2,5\% di level 5.498,54. Data BEI mencatat, saham PT Kalbe Farma Tbk (KLBF) mencatatkan kenaikan $1,23 \%$ (week on week/wow).
Saham PT Kimia Farma (persero) Tbk (KAEF) malah menguat tajam. Terhitung sepekan harga saham KAEF melesat 52,6\%.Sementara itu saham emiten jamu yakni PT Industri Jamu dan Farmasi Sido Muncul Tbk (SIDO) juga naik tapi lebih rendah dibanding IHSG dengan penguatan sebesar $0,81 \%$ (www.cnbcindonesia.com).

Untuk memilih saham yang akan dibeli, para investor umumnya melihat laporan keuangan yang di susun oleh perusahaan. Laporan Keuangan adalah informasi yang lazim dipakai oleh calon investor atau calon kreditur untuk mengambil sebuah keputusan. Informasi yang dihasilkan oleh laporan keuangan biasanya mengakibatkan adanya respon pasar. Respon pasar ini diperlihatkan dengan terdapatnya perubahan harga saham. Alat analisis yang biasa digunakan adalah analisis rasio. Analisis rasio adalah upaya yang dilakukan untuk memahami isi laporan keuangan perusahaan, untuk dapat mengetahui kelebihan dan kekurangan perusahaan. Analsis rasio yang biasa dipakai yaitu Debt to Assets Ratio (DAR), Inventory Turn Over (ITO) dan Earning Per Share (EPS).

Darsono (2005) menyebutkan Debt to Assets Ratio (DAR) menyediakan informasi tentang kemampuan perusahaan dalam mengadaptasi kondisi pengurangan aktiva akibat kerugian tanpa mengurangi pembayaran bunga pada kreditor. Sedangkan Inventory 
Turn Over (ITO) merupakan rasio yang digunakan untuk mengukur kecepatan perputaran persediaan menjadi kas. Semakin cepat inventory terjual, semakin cepat investasi perusahaan berubah dan persediaan menjadi kas (Robert Ang, 1997) dan Menurut Widoatmodjo (2007) Earning Per Share (EPS) merupakan rasio antara pendapatan setelah pajak dengan jumlah saham yang beredar".

Berdasarkan beberapa uraian di atas, maka peneliti berharap dapat melakukan penelitian lebih lanjut dengan mengkaji pengaruh Debt To Asset Ratio (DAR), Inventory Turnover (ITO) dan Earning Per Share (EPS) terhadap harga saham industri farmasi Indonesia. BEI.

\section{METODE}

Riset ini memakai pendekatan kuantitatif. Populasi dalam riset ini adalah 10 emiten subsektor farmasi. Data sampel memakai metode purposive sampling. Adapun kriteria tersebut yaitu:

1. Emiten subsektor farmasi yang terdaftar di BEI selama tahun 2015-2019.

2. Emiten yang mempublikasikan laporan keuangannya secara berurutan pada periode 2015-2019

Tabel 1. Kriteria Pemilihan Sampel

\begin{tabular}{lc}
\hline Kriteria Pemilihan Sampel & Jumlah \\
\hline $\begin{array}{l}\text { Emiten subsektor farmasi yang terdapat di BEI } \\
\text { periode 2015 - 2019 }\end{array}$ & 10 \\
Emiten yang tidak mempublikasikan laporan & $(1)$ \\
keuangannya secara berurutan periode 2015-2019 & \\
Jumlah Perusahaan $\times$ Periode & $9 \times 5$ \\
Jumlah Sampel & 45 \\
\hline
\end{tabular}

Dari 10 populasi perusahaan yang dipilih sebagai data sampel penelitian terdapat 9 perusahaan dikalikan 5 periode, sehingga jumlah sampel dari tahun 2015 hingga 2019 sebanyak 45 sampel. Variabel yang digunakan dalam riset ini adalah sebagai berikut:

Tabel 2. Definisi Operasional Variabel

\begin{tabular}{|c|c|c|}
\hline Variabel & Indikator & Skala \\
\hline \multirow[b]{2}{*}{ DAR } & Total Utang $(D e b t)$ & \multirow[b]{2}{*}{ Rasio } \\
\hline & Total Aset (Assets) & \\
\hline \multirow{2}{*}{ ITO } & Penjualan & \multirow{2}{*}{ Rasio } \\
\hline & $\begin{array}{l}\text { Rata - rata persediaan } \\
\text { Laba Setelah Pajak }\end{array}$ & \\
\hline EPS & $\mathrm{EPS}=\overline{\text { [lh Saham yang beredar }}$ & Rasio \\
\hline $\begin{array}{l}\text { Harga } \\
\text { Saham }\end{array}$ & $\begin{array}{c}\text { Harga saham ketika harga penutupan } \\
\text { pertahun }\end{array}$ & rasio \\
\hline
\end{tabular}

Adapun tes asumsi klasik yang dipakai yaitu tes normalitas, tes multikolinearitas dan tes heteroskedastisitas. Pengujian terhadap hipotesis dalam riset ini memakai analisis regresi berganda. Model persamaan analisis regresi dalam riset ini adalah sebagai berikut:

$\mathrm{Y}=\alpha+\beta 1 \mathrm{X} 1+\beta 2 \mathrm{X} 2+\beta 3 \mathrm{X} 3+\mathrm{e}$
Selanjutnya, peneliti akan melakukan tes pengaruh dengan tes $\mathrm{F}$, tes $\mathrm{t}$ dan tes koefisien determinasi. Tes $\mathrm{F}$ dilaksanakan dengan memakai derajat signifikan $(\alpha)$ sebesar 5\% atau 0,05 dan tes t dilaksanakan dengan memakai derajat signifikan $(\alpha)$ sebesar 5\% atau 0.05 dan derajat kebebasan (degree of freedom) atau $\mathrm{df}=(\mathrm{n}-\mathrm{k})$.

Koefisien determinasi memperlihatkan fluktuasi Y yang dijelaskan oleh pengaruh linier $X$. Rentang koefisien determinasi adalah dari nol hingga satu $\left(0 \leq R^{2} \leq 1\right)$. Jika $R^{2}$ sama dengan 0 , artinya tidak ada hubungan antara variabel bebas $(\mathrm{X})$ dan variabel terikat (Y). Jika $\mathrm{R}^{2}$ sama dengan 1 , berarti garis regresi yang terbentuk dapat memprediksi $\mathrm{Y}$ dengan sempurna. Semakin dekat angka R2 dengan angka 1 maka semakin kuat pengaruh variabel independen terhadap variabel dependen yang dapat dijelaskan.

\section{HASIL DAN PEMBAHASAN}

Berikut ini adalah perolehan hasil Statistik Deskriptif :

Tabel 3. Statistik Deskriptif Descriptive Statistics

\begin{tabular}{cccccc}
\hline & N & Terendah & Maximum & Mean & $\begin{array}{c}\text { Std. } \\
\text { Deviation }\end{array}$ \\
\hline X1 & 45 & .067 & .736 & .37756 & .200849 \\
X2 & 45 & .600 & 7519.556 & 787.44942 & 2237.768920 \\
X3 & 45 & -14.935 & 2608.132 & 225.76500 & 535.807470 \\
Y & 45 & 0 & 9200 & 2110.07 & 2202.109 \\
Valid N & 45 & & & & \\
\hline
\end{tabular}
bahwa :

Dari data pada tabel 3, maka dapat dijelaskan

a. Variabel DAR jumlah sampel sebanyak 45, memiliki angka mean sebesar 0,37756. Angka tertinggi sebesar 0,736 dan angka terendah sebesar 0.067 serta standar deviasi sebesar 0,200.

b. Variabel ITO jumlah sampel sebanyak 45, memiliki angka mean sebesar 787,45. Angka tertinggi sebesar 7619.6 dan angka terendah sebesar 0.600 serta standar deviasi sebesar 2237,8.

c. Variabel EPS jumlah sampel sebanyak 45 , memiliki angka mean sebesar 225,8. Angka tertinggi sebesar 2608,1 dan angka terendah sebesar 0 serta standar deviasi sebesar $-14,935$.

d. Variabel Harga Saham dengan jumlah sampel sebanyak 45, memiliki angka mean sebesar 2110,1. Angka tertinggi sebesar 9200 dan angka terendah sebesar 0 serta standar deviasi sebesar 2202,1.

Selanjutnya, adapun hasil tes normaitas data sebagai berikut: 
Umar Hamdan Nst, Syamsurizal dan Cut Zahri, Pengaruh Debt To Asset Ratio, Inventory dan Earning Per Share terhadap Harga Saham pada Industri Subsektor Farmasi yang Terdaftar di BEI

Tabel 4. Hasil Tes Normalitas

One-Sample Kolmogorow-Smirnow Test

\begin{tabular}{|ll|r|}
\hline & & $\begin{array}{r}\text { Unstandardiz } \\
\text { ed Residual }\end{array}$ \\
\hline Normal Parameters & Mean & 45 \\
& Std. Deviation & .0000000 \\
Most Extreme Differences & Absolute & $3.89664900 \mathrm{E} 3$ \\
& Positive & .144 \\
& Negative & .144 \\
Kolmogorow-Smirnov Z & & -.083 \\
Asymp. Sig. (2-tailed) & & .963 \\
\hline
\end{tabular}

a. Test distribution is Normal.

Hasil tes statistik Kolmogorov-Smirnov Test di atas, terlihat nilai Sig. sebesar 0,312>0,05. Maka Ha ditolak dan Ho diterima, artinya data telah berdistribusi normal. Tes normalitas selanjutnya dengan analisis grafik melalui grafik histogram dan normal probability plot.

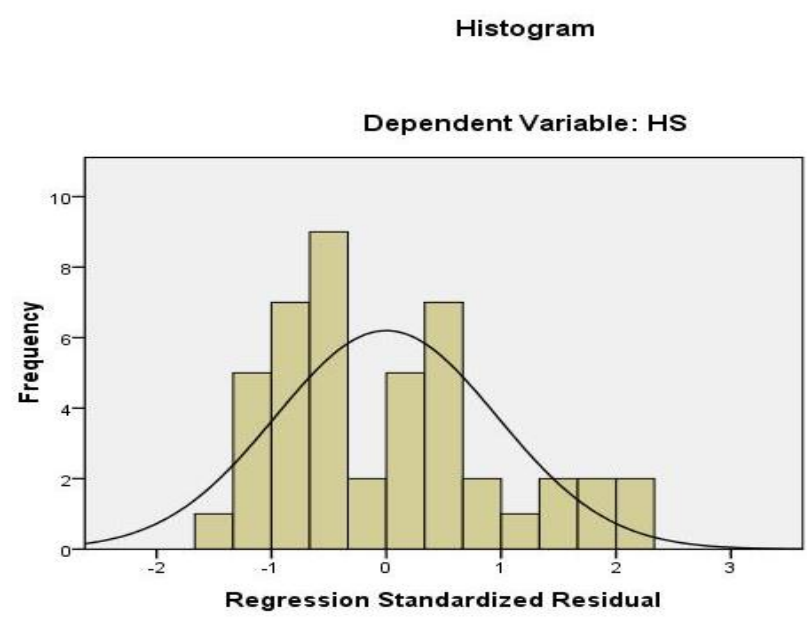

Gambar 1. Grafik Histogram

Normal P-P Plot of Regression Standardized Residual

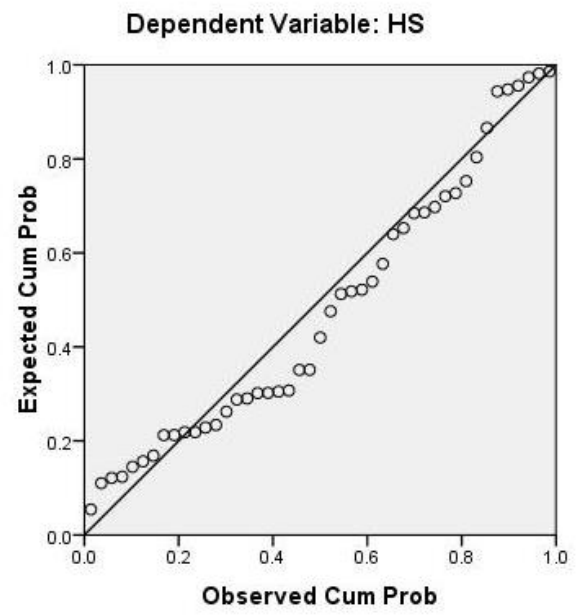

Gambar 2. Grafik Normal P-Plot
Pada histogram, terlihat distribusi data simetris pada bagian kiri dan kanan. Sementara pada grafik normal P-Plot, terlihat titik yang tersebar di sekitar garis diagonal. Maka disimpulkan bahwa distribusi data adalah normal. Hasil uji terhadap multikolinearitas pada riset ini dapat dilihat pada tabel berikut :

Tabel 5. Hasil Tes Multikolinieritas

\begin{tabular}{|c|c|c|c|c|c|c|c|c|}
\hline \multicolumn{9}{|c|}{ Coefficients $^{a}$} \\
\hline \multirow[b]{2}{*}{ Model } & & \multicolumn{2}{|c|}{ Unstandardized Coefficients } & \multirow{2}{*}{$\begin{array}{l}\text { Standardized } \\
\text { Coefficients } \\
\text { Beta }\end{array}$} & \multirow[b]{2}{*}{$t$} & \multirow[b]{2}{*}{ Sig. } & \multicolumn{2}{|c|}{ Collinearity Statistics } \\
\hline & & B & Std. Error & & & & Tolerance & $\mathrm{VIF}$ \\
\hline 1 & (Constant) & 1582.351 & 715.257 & & 2.212 & .033 & & \\
\hline & $\mathrm{x} 1$ & 568.589 & 1595.506 & .052 & 356 & .723 & .985 & 1.016 \\
\hline & $x_{2}$ & -.040 & 144 & -.040 & -.277 & .783 & .980 & 1.021 \\
\hline & $\times 3$ & 1.525 & .595 & 371 & 2.564 & .014 & .995 & 1.005 \\
\hline
\end{tabular}

Hasil data diatas, $\mathrm{X} 1, \mathrm{X} 2$ dan $\mathrm{X} 3$ memiiliki angka VIF lebih kecil dari 10 dan nilai tolerance $>0,1$. Maka dapat dikatakan tidak terjadinya multikolinieritas pada model regresi. Uji heteroskedastisitas terlihat pada grafik scatterplot dibawah:

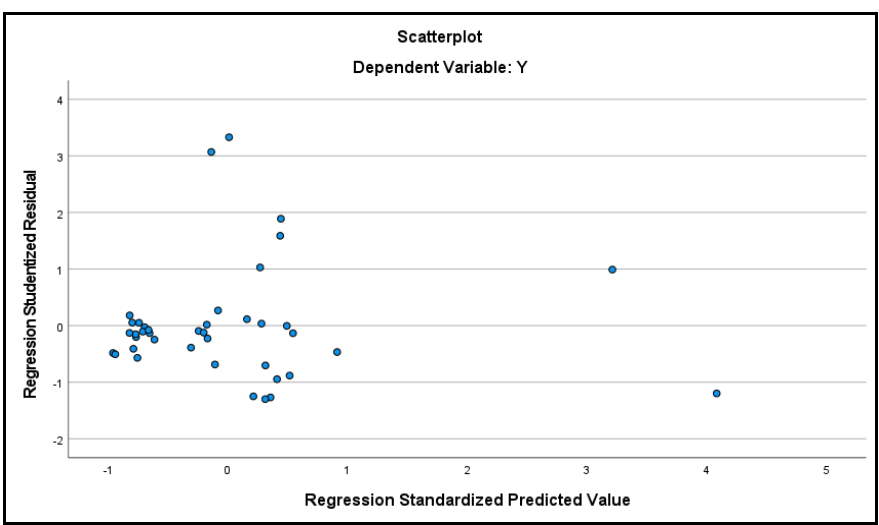

Gambar 3. Grafik ScatterPlot

Pada gambar terlihat titik-titik yang tersebar secara acak dan tidak membentuk pola tertentu. Hal ini memperlihatkan bahwa tidak adanya gejala heteroskedastisitas pada model regresi.

\section{Hasil Uji Hipotesis}

Hasil uji hipotesis dengan memakai tes $\mathrm{F}$ dapat dilihat pada tabel berikut:

Tabel 6. Hasil Tes Simultan (F)

$$
\text { ANOVA }^{a}
$$

\begin{tabular}{llrrrrr}
\hline & Model & Sum of Squares & df & Mean Square & F & Sig. \\
\hline & Regression & 47228355.456 & 3 & 15742785.152 & 3.569 & $.028^{b}$ \\
1 Residual & 114674763.744 & 26 & 4410567.836 & & \\
\multicolumn{1}{l}{ Total } & 161903119.200 & 29 & & & \\
\hline a. Dependent Variable: Y & & & & \\
b. Predictors: (Constant), X3, X1, X2 & & &
\end{tabular}

Hasil Tes F pada tabel 4.6, nilai sig. 0,05 (0,028 > 0,05), maka H1 diterima. Dengan demikian, dapat disimpulkan bahwa variabel independen DAR, ITO, dan EPS secara simultan berpengaruh signifikan terhadap harga saham. Hasil pengtesan hipotesis dengan memakai tes $t$ dapat dilihat pada tabel berikut: 
Tabel 7. Hasil Tes Parsial (t)

\begin{tabular}{|c|c|c|c|c|c|c|}
\hline \multirow[b]{3}{*}{ Model } & & \multicolumn{5}{|c|}{ Coefficients $^{\mathrm{a}}$} \\
\hline & & \multicolumn{2}{|c|}{ Unstandardized Coefficients } & \multirow{2}{*}{$\begin{array}{l}\text { Standardized } \\
\text { Coefficients } \\
\text { Beta }\end{array}$} & \multirow[b]{2}{*}{$\mathrm{t}$} & \multirow[b]{2}{*}{ Sig. } \\
\hline & & B & Std. Error & & & \\
\hline \multirow[t]{4}{*}{1} & (Constant) & 1307.824 & 767.899 & & 1.703 & .097 \\
\hline & $\mathrm{x} 1$ & 2256.875 & 1855.847 & .186 & 1.216 & .232 \\
\hline & $\mathrm{x} 2$ & -.071 & .143 & -.076 & -.498 & .622 \\
\hline & $\mathrm{X} 3$ & 1.313 & .595 & .337 & 2.209 & .034 \\
\hline
\end{tabular}

Bedasarkan hasil Tes Parsial (Tes t) pada tabel 4.7, maka dapat dijelaskan pengaruh variabel independen secara parsial yaitu :

1. Variabel DAR tingkat sig 0,232>0,05 maka Debt to Asset Ratio (DAR) secara parsial tidak berpengaruh signifikan terhadap harga saham.

2. Variabel ITO tingkat sig 0,622>0,05 maka Inventory Turnover (ITO) secara parsial tidak berpengaruh signifikan terhadap harga saham.

3. Variabel EPS tingkat sig 0,034 $<0,05$ maka Earning Per Share (EPS) secara parsial memiliki pengaruh positif signifikan terhadap harga saham. berikut :

Hasil tes koefisien determinasi adalah sebagai

Tabel 8. Hasil Tes R Square

\begin{tabular}{|c|c|c|c|c|c|}
\hline \multirow[b]{2}{*}{ Model } & \multicolumn{4}{|c|}{ Model Summary } & \multirow[b]{2}{*}{$\begin{array}{l}\text { Durbin- } \\
\text { Watson }\end{array}$} \\
\hline & $\mathrm{R}$ & R Square & $\begin{array}{l}\text { Adjusted R } \\
\text { Square }\end{array}$ & $\begin{array}{l}\text { Std. Error of } \\
\text { the Estimate }\end{array}$ & \\
\hline 1 & $.540^{\mathrm{a}}$ & .292 & .210 & 2100.135 & 1.096 \\
\hline
\end{tabular}

Hasil tes koefisien determinasi pada tabel 4.8 memperlihatkan angka $\mathrm{R}$ sebesar 0,540 yang berarti korelasi atau hubungan antara variabel dependen dengna variabel-variabel independen yang cukup kuat karena lebih besar dari 0,5 (50\%). Sementara angka Adjusted $R$ Square adalah 0,210. Angka ini mengindikasikan bahwa hanya $21 \%$ variasi atau perubahan dalam harga saham dapat dijelaskan oleh variasi variabel DAR, ITO dan EPS. Sementara sisanya sebesar $79 \%$ dijelaskan oleh variabel-variabel lain yang tidak dimasukkan dalam model riset.

\section{SIMPULAN}

Berdasarkan hasil riset dapat disimpulkan bahwa variabel Debt to Asset Ratio (DAR) secara parsial tidak berpengaruh signifikan terhadap harga saham. Selanjutnya variabel Inventory Turnover (ITO) secara parsial tidak berpengaruh signifikan terhadap harga saham. Namun, Earning Per Share (EPS) secara parsial memiliki pengaruh positif signifikan terhadap harga saham.

Pada hasil pengtesan koefisien determinasi memperlihatkan angka $\mathrm{R}$ sebesar 0,540 yang berarti korelasi atau hubungan antara variabel dependen dengna variabel-variabel independen yang cukup kuat karena lebih besar dari 0,5 (50\%). Sementara angka Adjusted $R$ Square adalah 0,210. Angka ini mengindikasikan bahwa hanya $21 \%$ variasi atau perubahan dalam harga saham dapat dijelaskan oleh variasi variabel DAR, ITO dan EPS. Sementara sisanya sebesar $79 \%$ dijelaskan oleh variabel-variabel lain yang tidak dimasukkan dalam model riset.

\section{DAFTAR PUSTAKA}

Ang, Robert. 1997. Buku Pintar Pasar Modal Indonesia (The Intelligent Guide to Indonesian Capital Market). Jakarta: Mediasoft Indonesia.

Darsono dan Ashari. 2005. Pedoman Praktis Memahami Laporan Keuangan. Yogyakarta : CV. Andi Offset

Widoatmojo, Sawidji. 2007. Cara Sehat Investasi di Pasar Modal. Jakarta: PT Elex Media Komputindo.

https://www.cnbcindonesia.com/market/2020030821575 5-17-143303/corona-bikin-saham-emiten-farmasimeroket-pekan-ini-gimana diakses 20 Maret 2020 www.idx.com 